\title{
Pencapaian Kompetensi Geometri Siswa dengan Pembelajaran Kooperatif Tipe Pair Checks dan Teams Games Tournament
}

\author{
Restiani $^{1 *}$, Ayu Wulandari ${ }^{2}$, Suyanto $^{2}$ \\ ${ }^{1}$ Guru Matematika MTs Negeri 30 Jakarta Timur, Indonesia \\ ${ }^{2}$ Pendidikan Matematika, STKIP Kusuma Negara, Indonesia \\ *restiani141@gmail.com
}

\begin{tabular}{|c|c|}
\hline Article Info & Abstract \\
\hline $\begin{array}{l}\text { Received } \\
17 \text { April } 2020\end{array}$ & $\begin{array}{l}\text { Students also have not been able to formulate interactions between } \\
\text { given elements, questions to be solved, and appropriate mathematical } \\
\text { concepts to solve the problem. As a result, the achievement of students' } \\
\text { geometry competencies is in the gap towards the goals. Therefore, this }\end{array}$ \\
\hline Revised & study aims to determine the differences in the achievement of geometry \\
\hline 29 April 2020 & $\begin{array}{l}\text { competence of students on plane geometry subject between cooperative } \\
\text { learning type Teams Games Tournament (TGT) and pair checks. This }\end{array}$ \\
\hline $\begin{array}{l}\text { Accepted } \\
30 \text { April } 2020\end{array}$ & $\begin{array}{l}\text { research was conducted on a sample of } 72 \text { people, that is } 36 \text { students } \\
\text { with TGT type cooperative learning and } 36 \text { students with pair checks } \\
\text { type learning. Samples were selected by cluster random sampling. This }\end{array}$ \\
\hline Keywords & $\begin{array}{l}\text { research is a quasi-experimental with posttest only nonequivalent } \\
\text { control group design. Quantitative data were obtained using test } \\
\text { instruments. Research data were analyzed by parametric statistics. }\end{array}$ \\
\hline Games Tournament & Based on data analysis, it was concluded that there were differences in \\
\hline Geometry Concept & achievement of students' geometry competencies between TGT type \\
\hline Pair Checks & $\begin{array}{l}\text { cooperative learning and pair checks on plane geometry subject. } \\
\text { Model pair checks is an alternative to learning geometry. }\end{array}$ \\
\hline
\end{tabular}

How to Cite:

Restiani., Wulandari, A., \& Suyanto. (2020). Pencapaian Siswa dengan Model Kooperatif

Pair Checks dan Teams Games Tournament pada Materi Bangun Datar. Journal of

Instructional Mathematics, 1(1), 11-19.

\section{PENDAHULUAN}

Matematika merupakan konsentrasi keilmuan dalam beberapa bidang seperti artimatika, geometri, statistika, dan kalkulus. Matematika merupakan ilmu dasar yang memiliki peranan penting dalam perkembangan ilmu pengetahuan dan teknologi. Pemahaman tentang konsep dasar dari beberapa bidang kajian matematika itu penting agar siswa dapat mengembangkan ilmu pengetahuan sehingga mudah meyelesaikan permasalahan-permasalahan yang bernuansa matematika dan biasa ditemui dalam kehidupan sehari-hari. Oleh karena itu, ada kebutuhan terhadap matematika yang melibatkan beberapa bidang kajian untuk pengembangan ilmu pengetahuan dan teknologi di kemudian hari. Namun, kondisi sekarang tidak jarang ditemukan adanya kesulitan siswa memahami matematika karena berawal dari konsep dasarnya (Rosilawati \& Alghadari, 2018; Alghadari \& Herman, 2018; ; Rahayu \& Alghadari, 2019). Selanjutnya Budiarti (2019) menyatakan bahwa jika dibandingkan dengan kompetensi lainnya, salah satu yang berada pada tingkat terendah adalah kompetensi geometri siswa. Kesulitan siswa terhadap matematika menumbuhkan kebutuhan untuk pengembangan pedagogi pembelajaran (Indah, 2017). 
Berdasarkan hasil observasi di salah satu sekolah di daerah Jakarta Timur, ditemukan nilai rata-rata UN tahun 2018 pada mata pelajaran matematika di sekolah tersebut mencapai 69,6 dengan nilai tertinggi 97,5 dan terendah 20. Kemudian, hasil observasi terhadap pencapaian kompetensi siswa pada materi bangun datar masih kurang idkarenakan pada materi ini banyak perhitungan aljabar dalam mencari penyelesaian masalah. Nilai rata-rata ulangan harian siswa pada materi geometri tersebut adalah 65,6 dengan presentase ketuntasan siswa mencapai 41,7 untuk Kriteria Ketuntasan Minimal (KKM) mata pelajaran matematika yang ditetapkan di sekolah itu adalah 71. Dengan kata lain, lebih dari setengah dari jumlah siswa keseluruhan dinyatakan belum melampaui KKM yang telah ditetapkan sekolah. Dalam bahasa yang sepadan dapat dikatakan bahwa lebih dari setengah jumlah siswa yang mengikuti ulangan harian tersebut belum mampu mencapai kompetensi geometri berdasarkan indikator-indikator tertentu.

Menurut studi Alghadari \& Herman (2018) dan Alghadari, Herman \& Prabawanto (2020) masalah yang mempengaruhi pencapaian kompetensi geometri siswa terhadap disebabkan oleh faktor-faktor seperti: aktivitas kognitif siswa ketika mengikuti pembelajaran masih belum tampak, aktivitas siswa ketika menyelesaikan soal-soal juga masih belum optimal, kadang-kadang siswa juga belum mampu merumuskan interaksi antara unsur-unsur yang diketahui, pertanyaan yang akan diselesaikan, dan konsep matematika yang tepat untuk menyelesaikan masalah. Di sisi lain, model yang diimplementasi saat pembelajaran adalah pendekatan yang bersifat konvensional. Pendekatan yang bersifat konvensional merupakan model pembelajaran yang bersifat klasik di mana siswa kurang berperan aktif dalam aktivitas pembelajaran, di mana sistem pembelajaran seperti tersebut hanya berlangsung dengan arah guru-siswa (Yantiani, Wiarta \& Putra, 2013). Pada kasus tersebut, moda pembelajaran sangat jarang memfasilitasi interaksi antar sesama siswa.

Proses belajar-mengajar matematika perlu diperhatikan agar tujuan dari pembelajaran matematika dapat tercapai. Proses belajar mengajar di kelas merupakan kegiatan yang paling pokok pada proses pendidikan di sekolah (Wulandari, 2018; Budiarti, 2019). Pangesti \& Retnowati (2017) menyatakan bahwa cara yang dapat dilakukan untuk mengembangkan kompetensi geometri siswa yaitu dengan memberikan materi pengayaan terutama bagi siswa yang telah menguasai kompetensi dasar minimal dan alokasi waktu pembelajaran mencukupi. Kegiatan mentransfer informasi dan ilmu pengetahuan dengan arah guru-siswa atau dari siswa-siswa dalam sebuah proses belajar mengajar merupakan kegiatan inti untuk mencapai sebuah tujuan belajar (Rosilawati \& Alghadari, 2018). Berhasil tidaknya proses belajar-mengajar untuk mencapai tujuan belajar dipengaruhi oleh beberapa faktor. Faktor-faktor yang dimaksud antara lain adalah kemampuan kognitif siswa itu sendiri, pendekatan dan pedagogi pembelajaran, kesiapan siswa menerima pelajaran (Wulandari, 2018; Rosilawati \& Alghadari, 2018; Indah, 2017; Rahayu \& Alghadari, 2019). Pemilihan pendekatan pembelajaran juga perlu diperhatikan supaya dapat mencapai tujuan tersebut secara optimal. Model dan pendekatan pembelajaran yang kurang tepat akan berpengaruh terhadap rendahnya pencapaian kompetensi siswa (Rosilawati \& Alghadari, 2018). Oleh karena itu salah satu alternatif dalam mengatasi masalah kesulitan belajar siswa adalah dengan menggunakan model yang dapat digunakan oleh guru untuk membangkitkan suasana belajar di kelas. 
Proses pembelajaran yang berkualitas dapat tercipta apabila siswa dan guru berpartisifasi aktif didalamnya. Siswa dan guru berinteraksi dalam suatu kegiatan yang disebut dengan pembelajaran. Ada berbagai pendekatan dan proses pembelajaran yang disarankan untuk pencapaian kompetensi siswa lebih baik (Huda, 2014; Shoimin, 2014). Pendekatan tersebut tentu saja berpusat pada siswa dengan mengoptimalkan potensi siswa unggul untuk membantu teman sekelasnya seperti yang dijelaskan dalam teori konstruktivisme sosial. Dua dari sejumlah model belajar siswa yang bertumpu pada teori konstruktivisme sosial tersebut adalah pembelajaran kooperatif tipe TGT (Yantiani, Wiarta \& Putra, 2013) dan pair checks (Muawanah, Budiyono \& Subanti, 2015). Melalui model kooperatif tipe TGT dan pair checks yang diimplementasikan maka potensi siswa dimaksimalkan untuk dapat mengatasi kesulitan belajar mereka (Syafi'i, 2018; Agustina, Rahmawati \& Deswita, 2019). Lebih lanjut, berdasarkan hasil studi Syafi'i (2018) bahwa pembelajaran TGT dapat meningkatkan hasil belajar matematika siswa, dan menurut studi Rahmawati (2017) bahwa dengan model TGT capainnya lebih dari model kooperatif lain. Namun menurut studi Kusuma \& Khoirunnisa (2018) bahwa pembelajaran TGT tidak lebih baik dari pada model pembelajaran kooperatif lainnya. Oleh karena itu, tujuan penelitian ini adalah untuk mengetahui apakah terdapat perbedaan pencapaian kompetensi geometri Siswa antara pembelajaran Kooperatif tipe TGT dan pair checks.

\section{METODE PENELITIAN}

Penelitian ini dilakukan dengan pendekatan kuasi eksperimen dengan posttest only nonequivalent control group design. Materi belajar dengan setting model kooperatif yang disampaikan yaitu tentang bangun datar. Penelitian ini dilakukan di Madrasah Tsanawiyah (MTs) Negeri di Jakarta Timur. Populasi target adalah seluruh siswa yang terdaftar di MTs. Populasi pada sekolah tersebut telah terklaster sesuai dengan jenjangnya. Ada tiga jenjang dalam populasi tersebut di mana salah satu jenjang merupakan populasi terjangkau penelitian ini. Sesuai dengan kurikulum pendidikan nasional dan materi geometri dalam matampelajaran matematika, maka populasi terjangkau untuk penelitian ini adalah seluruh siswa kelas VII sebanyak 180 siswa dari lima kelompok kelas yang ratarata jumlah siswa dalam tiap kelas terdiri dari 36 siswa.

Dari populasi terjangkau tersebut kemudian dipilih secara acak dua kelompok sampel yang akan diimplementasikan model pembelajaran kooperatif. Oleh karena itu, teknik pengambilan sampel dalam studi ini adalah cluster random sampling. Sampel yang terpilih adalah siswa kelas VIIA dan VIIB. Sampel adalah bagian dari populasi yang mempunyai ciri-ciri atau keadaan tertentu yang diteliti. Karena tidak semua data dan informasi akan diproses dan tidak semua orang atau benda akan diteliti melainkan cukup dengan menggunakan sampel yang representatif. Siswa yang tercatat sebagai peserta di kelas VIIA yang berjumlah 36 orang yang dijadikan sebagai kelompok pembelajaran kooperatif tipe TGT, dan kelas VIIB berjumlah 36 siswa yang dijadikan sebagai kelompok pembelajaran kooperatif tipe pair checks.

Penelitian ini terdiri dari dua variabel, yaitu variabel terikat dan variabel bebas. Variabel terikat dalam penelitian ini adalah pencapaian kompetensi geometri siswa. Sedangkan variabel bebasnya terdiri dari dua tipe pembelajaran 
kooperatif yaitu TGT dan pair checks. Alat ukur untuk melihat pencapaian kompetensi geometri siswa adalah menggunakan tes. Instrumen tes digunakan untuk memperleh data yang akan dianalisis menggunakan uji perbedaan dua ratarata dari salah satu statistik parametrik atau nonparametrik.

\section{HASIL DAN PEMBAHASAN}

Data Kelompok Pembelajaran Kooperatif TGT

Dari hasil penelitian, siswa kelompok pembelajaran kooperatif tipe TGT memperoleh rentang nilai antara 91 sebagai nilai maksimal dan 36,4 sebagai nilai minimal. Dari data tersebut diperoleh nilai rata-rata sebesar 71,72; median sebesar 72,42; dan modus sebesar 71,77; variansi sebesar 148,063, dan deviasi standarnya adalah 12,168. Berikut adalah Tabel distribusi frekuensi data pencapaian komptensi geometri siswa kelompok pembelajaran TGT.

Tabel 1. Distribusi Frekuensi Data Siswa Kelompok TG
\begin{tabular}{cccc} 
Kelas & Frekuensi & Titik Tengah & Batas Nyata \\
\hline $36-43$ & 1 & 39,5 & $35,5-43,5$ \\
\hline $44-51$ & 2 & 47,5 & $43,5-51,5$ \\
\hline $52-59$ & 2 & 55,5 & $51,5-59,5$ \\
\hline $60-67$ & 5 & 63,5 & $59,5-67,5$ \\
\hline $68-75$ & 13 & 71,5 & $67,5-75,5$ \\
\hline $76-83$ & 6 & 79,5 & $75,5-83,5$ \\
\hline $84-91$ & 7 & 87,5 & $83,5-91,5$ \\
\hline
\end{tabular}

Berdasarkan Tabel di atas, diketahui bahwa terdapat tujuh kelas interval nilai siswa dengan panjang kelasnya adalah delapan. Kemudian, merujuk pada Tabel tersebut, maka dibuat histogram dan poligon frekuensi seperti terlihat pada gambar berikut.

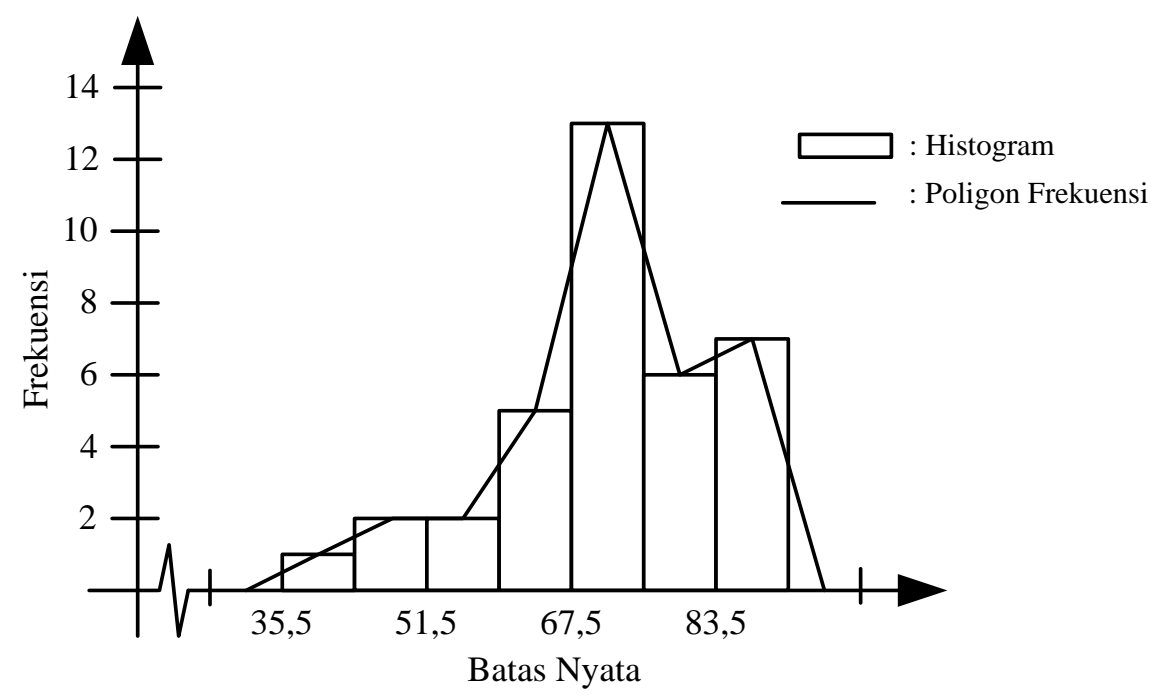

Gambar 1. Grafik Histogram dan Poligon Frekuensi Data Pencapaian Kompetensi Geometri Siswa Kelompok TGT 
Berdasarkan Tabel dan Grafik tersebut bahwa terdapat nilai tertinggi pada interval antara 84-91 sebanyak 7 siswa. Sedangkan nilai terendah antara 36-43 sebanyak 1 siswa. Jika dilihat berdasarkan nilai rata-rata diketahui siswa yang memperoleh nilai kurang dari nilai rata-rata adalah 15 siswa. Diketahui dari Tabel dan histogram, nilai median terletak di interval kelas 68-75 dengan frekuensi sebanyak 13, nilai yang berada di rata-rata sebanyak 21 siswa, nilai modus dari data tersebut terletak di interval kelas 68-75 dengan frekusensi sebanyak 13.

\section{Data Kelompok Pembelajaran Kooperatif Pair Checks}

Dari hasil penelitian, siswa kelompok pembelajaran kooperatif tipe pair checks memperoleh rentang nilai antara 95,5 sebagai nilai maksimal dan 50 sebagai nilai minimal. Dari data tersebut diperoleh nilai rata-rata sebesar 78,86; median sebesar 80,30; dan modus sebesar 82,50; variansi sebesar 117,095, dan deviasi standarnya adalah 10,821. Berikut adalah Tabel distribusi frekuensi data pencapaian komptensi geometri siswa kelompok pembelajaran kooperatif pair checks.

Tabel 2. Distribusi Frekuensi Data Siswa Kelompok Pair Check

\begin{tabular}{cccc}
\hline Kelas & Frekuensi & Titik Tengah & Batas Nyata \\
\hline $50-56$ & 1 & 53 & $49,5-56,5$ \\
\hline $57-63$ & 2 & 60 & $56,5-63,5$ \\
\hline $64-70$ & 6 & 67 & $63,5-70,5$ \\
\hline $71-77$ & 5 & 74 & $70,5-77,5$ \\
\hline $78-84$ & 10 & 81 & $77,5-84,5$ \\
\hline $85-91$ & 8 & 88 & $84,5-91,5$ \\
\hline $92-98$ & 4 & 95 & $91,5-98,5$ \\
\hline
\end{tabular}

Berdasarkan Tabel di atas, diketahui bahwa terdapat tujuh kelas interval nilai siswa dengan panjang kelasnya adalah tujuh. Kemudian, merujuk pada Tabel tersebut, maka dibuat histogram dan poligon frekuensi seperti terlihat pada gambar berikut.

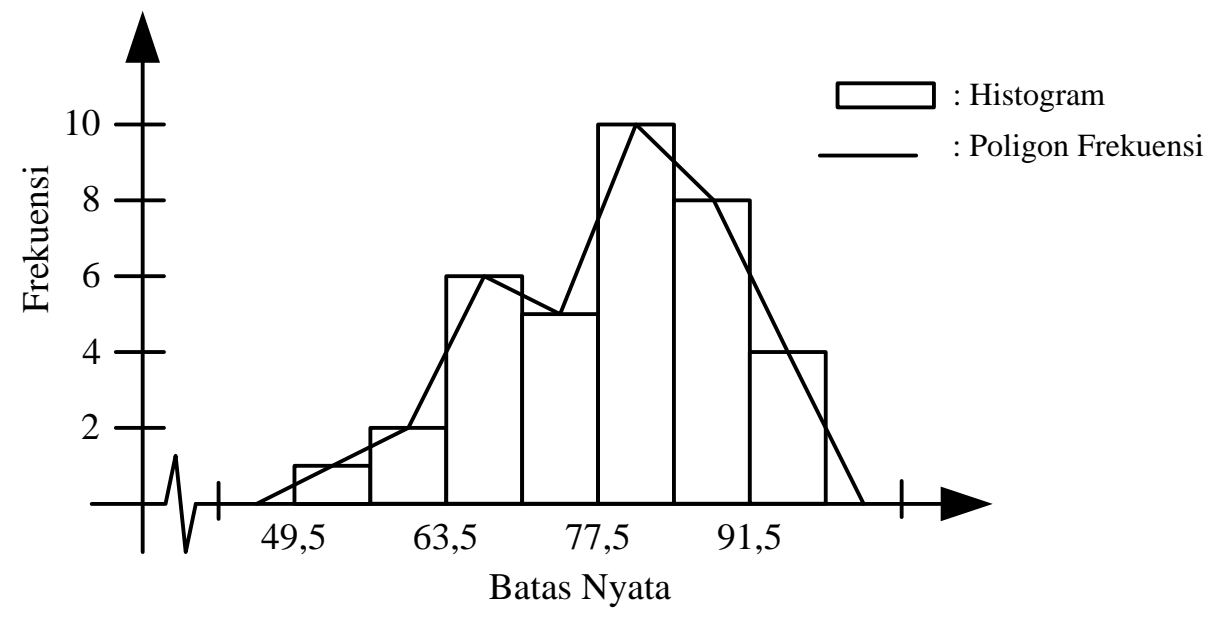

Gambar 1. Grafik Histogram dan Poligon Frekuensi

Data Pencapaian Kompetensi Geometri Siswa Kelompok Pair Checks 
Berdasarkan Tabel dan Grafik di atas, terdapat nilai tertinggi pada interval antara 92-98 sebanyak 4 siswa. Sedangkan nilai terendah antara 50-56 sebanyak 1 siswa. Jika dilihat berdasarkan nilai rata-rata diketahui siswa yang memperoleh nilai di bawah nilai rata-rata adalah 9 siswa. Diketahui dari Tabel dan Histogram, nilai median terletak di interval kelas 78-84 dengan frekuensi sebanyak 10, nilai yang berada di rata-rata sebanyak 27 siswa, nilai modus dari data tersebut terletak di interval kelas 78-84 dengan frekusensi sebanyak 10.

\section{Analisis Perbedaan Pencapaian Kompetensi Geometri}

Hipotesis penelitian yang diuji adalah terdapat perbedaan pencapaian kompetensi geometri siswa antara pembelajaran kooperaif tipe TGT dan pair checks. Berdasarkan hipotesis penelitian tersebut, maka hipotesis statistik yang dianalisis adalah rata-rata nilai pencapaian kompetensi geometri siswa kelompok pembelajaran TGT tidak sama dengan pencapaian siswa kelompok pair checks. Uji hipotesis tersebut akan dilakukan dengan statistik parametrik sehingga ada analisis persyaratan yang akan dipenuhi, yaitu uji normalitas distribusi data dan homogenitas variansi.

Uji normalitas menggunakan dengan uji Chi-Kuadrat. Dari perhitung uji normalitas pada data siswa kelompok pembelajaran TGT diperoleh $x_{\text {hitung sama }}^{2}$ dengan 7,322. Sedangkan $x_{\text {tabel }}^{2}$ pada taraf signifikansi 0,05 adalah sama dengan 12,592. Nilai $x^{2}$ hitung data kelompok pembelajaran TGT kurang dari $x_{\text {tabel }}^{2}$ sehingga data berdistribusi normal. Sementara dari perhitung uji normalitas pada data siswa

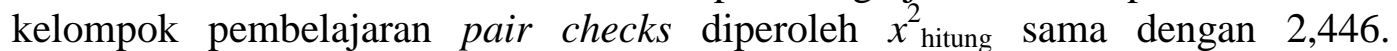
Sedangkan $x_{\text {tabel }}^{2}$ pada taraf signifikansi 0,05 adalah sama dengan 12,592 . Nilai $x^{2}{ }_{\text {hitung }}$ data kelompok pembelajaran kooperatif tipe pair checks kurang dari $x_{\text {tabel }}^{2}$ sehingga datanya juga berdistribusi normal. Selanjutnya, uji homogenitas dilakukan dengan uji Fisher. Kriteria ujinya adalah jika $F_{\text {hitung kurang dari atau }}$ dama dengan $F_{\text {tabel }}$ maka variansi data dari dua kelompok pembelajaran adalah

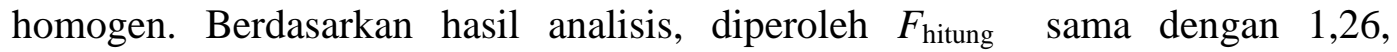
sedangkan $F_{\text {tabel }}$ sama dengan 1,76. Dengan demikian, disimpulkan bahwa varians kedua kelompok sama atau homogen. Dari hasil uji persyaratan analisis statistik yang meliputi uji normalitas dan uji homogenitas, dan telah diketahui bahwa data kedua kelompok pembelajaran distribusi normal serta variansinya homogen, sehingga analisis dilanjutkan dengan uji- $t$ untuk uji hipotesis penelitian.

Hasil perhitungan uji- $t$ berdasarkan analisis data, maka diperoleh $t_{\text {hitung }}$ sama dengan -2,645 dan $t_{\text {tabel }}$ pada taraf signifikansi 0,05 sama dengan 1,997. Dengan demikian, maka disimpulkan terdapat perbedaan nilai rataan pencapaian kompetensi geometri siswa kelompok pembelajaran TGT dan pair checks. Lebih lanjut, hasil analisis uji pos-Hoc menyatakan bahwa nilai rata-rata siswa kelompok pembelajaran pair checks lebih dari nilai rataan siswa kelompok pembelajaran TGT. Jadi, pencapaian kompetensi geometri siswa dengan pembelajaran pair checks lebih baik dari pada siswa kelompok pembelajaran TGT.

Data dari kedua hasil penelitian diperoleh yang memiliki pencapaian terbaik dalam rata-rata kompetensi geometri pada materi bangun datar terdapat di kelas yang menerapkan model pair checks. Dalam implementasi pembelajaran pair checks, siswa lebih terfokus untuk berdiskusi materi belajar karena pembentukan jumlah anggota kelompok yang lebih sedikit dibanding dengan model TGT. 
Namun bukan berati model TGT tidak lebih baik dibandingkan model pair checks. Hanya saja dalam hasilnya bahwa rata-rata nilai pencapaian kompetensi geometri yang lebih tinggi terjadi di kelompok siswa dengan pembelajaran pair checks. Di sisi lain, hasil analisis data keduanya sama-sama melampaui nilai KKM yang telah ditetapkan sekolah.

\section{Interpretasi Hasil Penelitian}

Berdasarkan hasil penelitian, disimpulkan bahwa terdapat perbedaan pencapaian kompetensi geometri siswa antara pembelajaran kooperatif tipe TGT dan pair checks pada materi bangun datar. Hasil studi ini tidak berbeda dengan hasil studi Kusuma \& Khoirunnisa (2018) bahwa pembelajaran TGT tidak lebih baik dari pada model pembelajaran kooperatif lain. Oleh karena itu, hasil studi ini juga bertentangan dengan hasil studi Rahmawati (2017) bahwa dengan model TGT capainnya lebih dari model kooperatif lain. Lebih lanjut, hasil studi ini sesuai dengan pernyataan Syafi'i (2018) bahwa pembelajaran TGT dapat meningkatkan hasil belajar matematika siswa, yang ditandai dengan pencapaian siswa telah melampaui nilai KKM. Dalam hal ini, pencapaian kompetensi dapat diartikan sebagai tingkat keberhasilan siswa dalam mempelajari materi pelajaran di sekolah yang dinyatakan dalam skor yang diperoleh dari hasil tes mengenai sejumlah materi pelajaran tertentu (Susanto, 2015). Pencapaian kompetensi digunakan sebagai tolak ukur keberhasilan siswa yang dapat dilihat dari skor nilai yang siswa peroleh melalui beberapa tes pada suatu materi pelajaran, apakah siswa selama pembelajaran mampu memahami atau tidak memahami apa yang di ajarkan.

Pembelajaran matematika bukan sekedar memberitahu mengenai rumus-rumus dan contoh penyelesaian masalah tetapi siswa perlu melakukan sebuah tindakan dan perbuatan berupa latihan-latihan untuk memberikan stimulus berpikirnya agar pemikiran siswa dapat berkembang dan lebih memahami arti dari konsep matematika yang mereka pelajari. Model pembelajaran adalah kerangka konseptual yang menggambarkan prosedur sistematis dalam mengorganisasikan pengalaman belajar untuk mencapai tujuan belajar tertentu dan berfungsi sebagai pedoman bagi para perancang pembelajaran dan para pengajar dalam merencanakan aktivitas belajar mengajar (Shoimin, 2014). Model pembelajaran merupakan sebuah prosedur yang sistematis untuk menjalankan sebuah kegiatan pembelajaran yang di sesuikan dengan kondisi kelas guna mencapai tujuan belajar dan sebagai pedoman bagi setiap guru maupun pengajar dalam menjalankan proses kegiatan belajar mengajar.

TGT merupakan salah satu tipe model pembelajaran kooperatif yang menitikberatkan permainan dan turnamen untuk mencapai ketuntasan belajar (Syafi'i, 2018). Model pembelajaran TGT merupakan salah satu model pembelajaran kooperatif yang memiliki ciri khas permain turnamen pada langkah pembelajarannya, dapat disimpulkan bahwa model pembelajaran ini merupakan model kooperatif yang melibatkan aktivitas seluruh siswa tanpa adanya perbedaan status dimana setiap anggota kelompok dapat membantu satu sama lain untuk mencapai keberhasilan belajar. Slavin (dalam Huda, 2014) menemukan bahwa TGT berhasil meningkatkan keterampilan dasar pencapaian, interaksi positif antarsiswa, harga diri dan sikap penerimaan pada siswa-siswa lain yang berbeda. Konsep utama dari model TGT adalah kerjasama untuk memperoleh tujuan belajar pembelajaran tutor sebaya untuk saling membantu dalam kesulitan 
memahami materi memunculkan interaksi positif antar siswa memunculkan sikap penerimaan dan saling menghargai jika ada perbedaan-perbedaan yang timbul. Adapun tahapan pembelajaran TGT dalam Syafi'i (2018) yaitu : 1) class presentation; 2) teams; 3) games; 4) tournament.

Menurut Herdian (dalam Shoimin, 2014), model pair checks (pasangan mengecek) merupakan model pembelajaran dimana siswa saling berpasangan dan menyelesaikan persoalan yang diberikan. Konsep utama dalam model pembelajaran pair cheks adalah pasangan mengecek setiap pasang yang terbentuk dalam satu kelompok saling mengecek pekerjaan mereka satu sama lain (Yantiani, Wiarta \& Putra, 2013). Menurut Huda (2014), model pembelajaran ini menerapkan pembelajaran kooperatif yang menuntut kemandirian dan kemampuan siswa dalam menyelesaikan persoalan. Lebih lanjut, model pembelajaran pair check memiliki gaya belajar tutor sebaya yang setiap anggota kelompok maupun pasangan memberikan dukungan dan saling mengajarkan dan memberikan pemahaman kepada anggota kelompok dan pasangannya untuk memahami materi maupun mengerjakan soal yang diberikan oleh guru, oleh karena itu memunculkan kemampuan yang mandiri pada setiap siswa. Adapun tahapan pembelajaran pair checks yaitu: 1) pembentukan kelompok inti; 2) pemecahan kelompok menjadi pelatih dan patner; 3) diskusi pasangan kelompok; 4) diskusi kelompok.

\section{KESIMPULAN}

Berdasarkan analisis data hasil penelitian maka dapat disimpulkan bahwa terdapat perbedaan pencapaian kompetensi geometri siswa antara pembelajaran kooperatif tipe TGT dan pair checks. Pencapaian kompetensi geometri siswa kelompok pembelajaran kooperatif tipe pair checks lebih dari pencapaian kompetensi geometri siswa kelompok pembelajaran kooperatif tipe TGT. Penerapan kedua model pembelajaran ini telah melampaui nilai KKM yang telah ditentukan sekolah terhadap mata pelajaran matematika. Dengan demikian, pembelajaran kooperatif tipe pair checks adalah salah satu alternatif untuk belajar pada materi geometri lebih baik dari pada TGT.

\section{UCAPAN TERIMA KASIH}

Penulis mengucapkan terima kasih kepada Ibu Ayu Wulandari, M.Pd dan Bapak Suyanto, M.M atas bimbingan yang diberikan dengan sabar dan ikhlas.

\section{REFERENSI}

Agustina, T., Rahmawati, N. K., \& Deswita, D. (2019). Perbedaan Hasil Belajar Matematika Siswa Antara Model Team Assisted Individualization dan Teams Games Tournament. Prosiding Seminar Nasional Pendidikan STKIP Kusuma Negara, 1(1), 1-5.

Alghadari, F., \& Herman, T. (2018). The obstacles of geometric problem-solving on solid with vector and triangle approach. Journal of Physics: Conference Series, 1132(1), 012046. https://doi.org/10.1088/1742-6596/1132/1/012046 
Alghadari, F., Herman, T., \& Prabawanto, S. (2020). Factors Affecting Senior High School Students to Solve Three-Dimensional Geometry Problems. International Electronic Journal of Mathematics Education, 15(3), em0590. https://doi.org/10.29333/iejme/8234

Huda, M. (2014). Model-Model Pengajaran dan Pembelajaran. Yogyakarta: Pustaka Pelajar.

Indah, M. E. B. (2017). Analisis Proses Pemecahan Masalah Geometri Berdasarkan Teori Van Hiele di Sekolah Menengah Atas. Jurnal Noken: IlmuIlmu Sosial, 2(1), 28-39. https://doi.org/10.33506/jn.v2i1.24

Kusuma, A. P., \& Khoirunnisa, A. (2018). Penerapan Model Pembelajaran Kooperatif Tipe Make a Match dan Team Games Tournament terhadap Hasil Belajar. Numerical: Jurnal Matematika dan Pendidikan Matematika, 2(1), 16. https://doi.org/10.25217/numerical.v2i1.186

Muawanah, L., Budiyono, B., \& Subanti, S. (2015). Eksperimentasi Model Pembelajaran Penemuan Terbimbing, Pair Checks, Dan Think Pair Share Pada Materi Bangun Ruang Sisi Datar Ditinjau Dari Gaya Belajar. Jurnal Pembelajaran Matematika, 3(6), 625-636.

Pangesti, F. T. P., \& Retnowati, E. (2017). Pengembangan Bahan Ajar Geometri SMP Berbasis Cognitive Load Theory Berorientasi pada Prestasi Belajar Siswa. Pythagoras, 12(1), 33-46. http://dx.doi.org/10.21831/pg.v12i1.14055

Rahayu, T., \& Alghadari, F. (2019). Identitas Bayangan Konsep Limas: Analisis Terhadap Konsepsi Matematis Siswa. Inomatika, 1(1), 21-30. https://doi.org/ 10.35438/inomatika.v1i1.134

Rahmawati, N. K. (2017). Implementasi Teams Games Tournaments dan Number Head Together ditinjau dari Kemampuan Penalaran Matematis. Al-Jabar: Jurnal Pendidikan Matematika, 8(2), 121-134. https://doi.org/10.24042/ajpm. v8i2.1585

Rosilawati, R., \& Alghadari, F. (2018). Konsepsi Siswa pada Suatu Bentuk Bangun Ruang Terkait dengan Rusuk dan Diagonal Sisi. Prisma, 7(2), 164176. https://doi.org/10.35194/jp.v7i2.459

Shoimin, A. (2014). 68 Model Pembelajaran Inovatif Dalam Kuikulum 2013. Yogyakarta: Ar-Ruzz Media.

Susanto, A. (2015). Teori Belajar dan Pembelajaran di Sekolah Dasar. Jakarta: Prenadamedia.

Syafi'i, M. (2018). Semangat Literasi Matematika pada Pengembangan Model Pembelajaran Kooperatif Teams Games Tournament (TGT) Guna Meninggkatkan Hasil Belajar Matematika Siswa. Jurnal Ilmu Pendidikan (JIP) STKIP Kusuma Negara, 9(2), 85-94.

Wulandari, A. (2017). Pengaruh Pemberian Tes Formatif yang Diberikan Umpan Balik terhadap Hasil Belajar Matematika Siswa di SMP Negeri 88 Jakarta. Jurnal Ilmu Pendidikan (JIP) STKIP Kusuma Negara, 8(2), 35-48.

Yantiani, N. M., Wiarta, I. W., \& Putra, M. (2013). Pembelajaran kooperatif pair check berpengaruh terhadap hasil belajar materi bangun ruang dan bangun datar siswa Kelas IV Gugus IV Semarapura. Mimbar PGSD Undiksha, 1(1), 110. http://dx.doi.org/10.23887/jjpgsd.v1i1.1188 